\title{
Mortality and associated risk factors for older adults admitted to the emergency department: a hospital cohort
}

\author{
Carmen García-Peña ${ }^{1 *}$, Mario Ulises Pérez-Zepeda ${ }^{1}$, Leslie Viridiana Robles-Jiménez² , Sergio Sánchez-García ${ }^{3}$, \\ Ricardo Ramírez-Aldana ${ }^{4}$ and Pamela Tella-Vega ${ }^{1}$
}

\begin{abstract}
Background: Older emergency department patients are more vulnerable than younger patients, yet many risk factors that contribute to the mortality of older patients remain unclear and under investigation. This study endeavored to determine mortality and factors associated with mortality in patients over 60 years of age who were admitted to the emergency departments of two general hospitals in Mexico City.

Methods: This is a hospital cohort study involving adults over 60 years of age admitted to the emergency department and who are beneficiaries of the Mexican Institute of Social Security and residents of Mexico City. All causes of mortality from the time of emergency department admission until a follow-up home visit after discharge were measured. Included risk factors were: socio-demographic, health-care related, mental and physical variables, and in-hospital care-related. Survival functions were estimated using Kaplan-Meier curves. Hazard ratios $(\mathrm{HR})$ were derived from Cox regression models in a multivariate analysis.
\end{abstract}

Results: From the 1406 older adults who participated in this study, 306 (21.8\%) did not survive. Independent mortality risk factors found in the last Cox model were age ( $H R=1.02,95 \% \mathrm{Cl}, 1.005-1.04 ; p=0.01)$, length of stay in the $\mathrm{ED}(\mathrm{HR}=1.003,95 \% \mathrm{Cl}=0.99,1.04 ; p=0.006)$, geriatric care trained residents model in Hospital $\mathrm{A}$ (protective factor) $(\mathrm{HR}=0.66,95 \% \mathrm{Cl}=0.46,0.96 ; p=0.031)$, and the FRAIL scale (HR of $1.3495 \% \mathrm{Cl}, 1.02-1.76 ; p=0.033$ ).

Conclusions: Risk factors for mortality in patients treated at Mexican emergency departments are length of stay and variables related to frailty status.

Keywords: Acute care, Emergency medicine, Geriatrics, Mortality

\section{Background}

Around the world, aging populations pose major challenges to societies and their health care systems. The health needs of older individuals will continue to grow and have greater impact on the financial, social, and health systems of most countries, with developing countries experiencing the greatest impact. This will create an unprecedented situation for our global society [1]. The health care requirements of aging individuals are broad, ranging from ambulatory clinical services, home

\footnotetext{
* Correspondence: mcgarciapena@gmail.com; mcgarcia@inger.gob.mx ${ }^{1}$ Dirección de Investigación, Instituto Nacional de Geriatría, Periférico Sur No. 2767, Mexico City, Mexico

Full list of author information is available at the end of the article
}

health visits, and acute hospitalization to long term and palliative care [2]. Health care systems are not responding effectively or efficiently [3] because they are not equipped to handle the increased needs of older adults, particularly since they were designed to treat the injuries or acute medical conditions of a younger population [4].

Existing literature reveals that older adults may experience increased vulnerability [5] in emergency departments (ED) because of a deficient response in services [6]. Global Aging and Adult Health (SAGE) [7] collected data via nationally representative population surveys in six middle-income countries: China, Ghana, India, Mexico, Russia, and South Africa. The data reported a prevalence of multimorbidity of $29.6 \%$ in the $70+$ age group in Mexico, one of the highest rates among the

(c) The Author(s). 2018 Open Access This article is distributed under the terms of the Creative Commons Attribution 4.0 International License (http://creativecommons.org/licenses/by/4.0/), which permits unrestricted use, distribution, and reproduction in any medium, provided you give appropriate credit to the original author(s) and the source, provide a link to the Creative Commons license, and indicate if changes were made. The Creative Commons Public Domain Dedication waiver (http://creativecommons.org/publicdomain/zero/1.0/) applies to the data made available in this article, unless otherwise stated. 
populations studied. Additionally, in the six countries included in the study, individuals who had been hospitalized over the past three years had a higher likelihood of contracting non-communicable diseases. A separate study also reported that adults over the age of 60 accounted for between 13 and 18\% of visits to the ED in Mexico [8]. Data from other studies shows that $14 \%$ of ED visits correspond to the 60+ age group $[9,10]$.

A combination of intrinsic and extrinsic factors work together to increase the mortality rate of this age group [11]. One of the main factors is the ability of health care workers to effectively assess the risk factors associated with mortality; a complex picture driven by the heterogeneous patterns of morbidity of this age group and the interactions with conditions particular to aging that preclude or delay risk stratification or that make assessment less accurate than in other age groups [12]. Older adults seek care in the ED for varied reasons and very often they present interacting conditions, a result of the convergence of multimorbidity with so-called geriatric syndromes (delirium, cognitive impairment, falls, incontinence, abuse, and mobility disability) [13].

Nevertheless, it is undeniable that identifying the risk factors for mortality in older adults could guide and individualize interventions for those patients most in need [14]. In fact, exposure to the ED and subsequent hospitalization may itself be considered a risk factor. Adults older than 65 years represent nearly half of the mortality cases in EDs $[15,16]$. As stated by de Decker et al., an emergency department is not only a place to care for old people, but also a place to die [17]. Therefore, it is imperative to determine which specific risk factors may contribute to the mortality of older adults who visit the ED.

In this study, we aimed to determine mortality and the associated factors in older adults ( $>60$ years of age) who were admitted to the ED in two general hospitals in Mexico City. Both hospitals were part of the Instituto Mexicano del Seguro Social (Mexican Institute of Social Security, or IMSS) system.

\section{Methods}

This report was based on a quasi-experimental study named "Old Persons in the Emergency Services of General Hospitals: Effectiveness of a Geriatric Care Training Model for Residents to Improve Health Results," registered at clinicaltrails.gov (NCT01706133). Two general hospitals were included and a training model was carried out in one of them. Basal and final cohorts of patients were integrated. The main aim of the study was to test an intervention based on geriatric care training of emergency care resident physicians in order to reduce frailty levels. In this present report, we considered all patients included. The geriatric care training model was only analyzed as an additional explanatory variable for mortality.
The eligible population was made up of adults over 60 years of age who visited the ED in one of two IMSS general hospitals in Mexico City. IMSS is a mandatory social security system that offers a comprehensive package of benefits to roughly half of the population in Mexico, including healthcare at all levels, as well as social and economic benefits (e.g., retirement pensions). IMSS covers the needs of non-governmental workers and their families. The IMSS health care system assigns each individual and immediate family member to a Family Medicine Unit, which is the primary health care provider, with secondary and tertiary health care provided as needed based on referrals from the Family Medicine Unit.

Participants were included in the study after being evaluated by a physician in triage and subsequently being admitted to the ED. The research team did not interfere with the medical decisions made in triage nor in the ED admission process. Patients with an imminent, acute, life-threatening condition that required immediate attention (intensive care), victims of a car accident, or patients who suffered second- or third-degree burns were not included.

The sample selection process was done consecutively, with the sample size calculated for the intervention project with an expected difference of $20 \%$ between the proportion of basal and final frailty. A lowering in frailty levels was the outcome of interest, with an alpha of 0.05 and a beta of 0.20 for a total of 480 patients and an additional $20 \%$ for possible loss during follow-up. The total sample size was included in the present study. This sample size was sufficient to determine mortality risk factors, which is the aim of the present report.

The main outcome was to determine overall mortality (all causes of death), independent of the site of occurrence (e.g., in the emergency department, post-ED hospitalization, or at home after discharge). Research staff collected this information at the hospital during the ED visit or post-ED hospitalization, or with next-of-kin at home. The first day of survival was recorded as the date admitted to the ED and the final follow-up was at 120 days after the visit to the ED. We chose 120 days as the cut off for follow up because we believe 120 days gave us enough timing to gather valid statistics while taking into consideration that the cut off for follow up also needed to be close enough to the date of ED admission for any deaths to be attributable to the ED visit.

In order to assess mortality risk factors, a set of independent variables from different dimensions was explored: the individual dimension included socio-demographic aspects such as age, sex, education, marital status, living condition, type of insurance, and financial position. A second dimension of variables was related to the health service provided during the current event and included: waiting time (in hours) in the ED, the number of previous visits to 
the ED (related or not to the medical reason for the current ED visit) during the six months prior to the current visit, the number of visits to the Family Medicine Clinic (prior to the current ED visit and for the same medical reason), whether there was a delay in seeking care at the ED for any reason (yes or no), the length of stay (in hours) in the ED, and finally, the model of residents trained in geriatric care (intervention) or referral for hospitalization in the same facility. The dimension of health-related variables included: main diagnosis upon admission, whether there was a presence of delirium (evaluated through the Confusion Assessment Method [CAM] [18], the current level of pain (evaluated with a 10-point Visual Analogue Scale for Experimental Pain with 10 being a maximum) [19], handgrip strength (assessed with a handheld electronic dynamometer adjusted for gender, with a cutoff mark of $17 \mathrm{~kg}$ for women and $30 \mathrm{~kg}$ for men) [20], whether the individual had suffered falls within the last year (yes or no), the total number of medications currently taken, the presence of depressive symptomatology (measured with the Brief Depression Screen developed for older people in ED) [21] and finally, morbidity (summatory of chronic diseases). Additional health-related variables included whether there was cognitive impairment, assessed with a valid Spanish-language version [22] of the Folstein [23] Mini-Mental State Examination (MMSE). The MMSE evaluates memory, orientation to space and time, ability to perform calculations, language and word recognition, with scores ranging from 0 to 30 points and lower scores indicating poorer cognitive ability. The cut off point for inclusion in the study was $\leq 23$, adjusted by age. Functionality was measured with the Barthel index [24] where a score of 100 means independence. The risk of adverse future events index was measured by the Identification of Seniors at Risk (ISAR) scale [25], with a positive score of 2 or more from a total of 6 points. Finally, the frailty status of participants was measured with the FRAIL scale, composed of 5 items (fatigue, resistance, ambulation, illness, and loss of weight) frailty considered present with 2 or more points [26].

\section{Procedures}

Once admitted to the ED by hospital staff, each patient was evaluated by properly trained nurses from the research team to determine whether the patient met the selection criteria. If so, written consent was obtained, baseline measurements were taken, and a questionnaire was completed within the first two hours of admission to the ED. Patients were monitored throughout their ED stay by the research nursing team to record if the hospital staff decided to discharge or hospitalize the patient and to record the participants' vital signs. A follow-up evaluation was conducted in participants' homes 120 days after admission to the ED. In cases where participants had died, primary caregivers, as proxies, were interviewed for the follow-up. The questionnaires were processed and reported by third parties who were not involved in the project and therefore did not possess any knowledge of the study. The data collection was carried out from June, 2013 to February, 2014.

\section{Ethical issues}

The research protocol was approved by the Ethics and Scientific Commission of IMSS (R2011-785-056). An informed written consent was signed by each willing participant or by the participant's representative. It was made clear that patients were free to refuse to take part in the study or to withdraw from the study at any point by submitting a simple request. Patients were also advised that they would experience no consequence or alteration to the medical care provided if they refused to participate or withdrew after having previously begun to participate.

\section{Statistical analysis plan}

Censored cases included surviving individuals and those who dropped out of the study or were excluded, and uncensored included those patients who died. Survival time was determined from the date the patient was admitted to the ED for initial observation [27] up to 120 days later. The final time for uncensored individuals represented the date of death at any time between admission for observation and the study end date, which corresponded to the period in which evaluation was performed at home. For censored individuals, the end time was the date of the final home visit because, although, there were individuals who withdrew from the study and therefore did not fill out the questionnaires, they were determined to be alive. There were cases in which information was obtained after the end of the study, however 120 days was considered as the cutoff time for all survival analysis. Considering this information and five additional cases (4 were patients who died) without recorded dates, 48 cases were removed from the survival analyses. Cases were removed based on missing values in the involved variables and no data input was performed on those cases.

Descriptive and bivariate analyses (between the censored and uncensored patients) was performed according to the type of variable. If the variable was nominal or ordinal, a chi-squared test was performed; if the variables were qualitative or ordinal with multiple values, $\mathrm{t}$-tests were used; if normality was inadequate, the Mann-Whitney test and medians were used.

Survival functions were estimated through Kaplan-Meier curves (KMC). To determine significant differences, comparisons of survival curves were performed applying log-rank tests. To conduct the comparisons, qualitative variables were used when possible, and, when necessary, new categorized variables were obtained from quantitative variables [27]. 
Age groups, years of formal education groups $(0,1-6$, 7-12 and > 12) and handgrip strength (categorized as abnormal according to the description in the methods section) in the ED on completion of the KMC were included.

Those variables that were significantly different according to vital status were selected to perform a Cox regression (27). The models were simplified according to the significance of the variables, leaving only some control variables (e.g., age and sex). The effect of the intervention-trained residents for the geriatric care model (see above intervention) was added as a factor, which was obtained by taking into consideration the hospital in which the intervention was carried out.

\section{Results}

Flow of study participants is presented in Fig. 1. During the study period (from June, 2013 to February, 2014), a total of 3119 patients 60 years and older arrived in the ED. Of these, 1055 were checked by the social worker at reception triage and sent back to their home, 279 were referred to another hospital, and 373 were admitted to an area named "short stay unit" (a consultation room for minor procedures such as bandaging, receiving a prescribed medication injection, minor wound healing, or any other non-life threatening condition). No participant was eliminated due to an acute, life-threatening condition because such conditions are not treated in general hospitals such as the hospitals included in the study. This study evaluated a total of 1406 adults 60 -years or older who were admitted to EDs in one of two hospitals. $N=705$ in Hospital A (50.14\%) and $n=701$ in Hospital B $(49.86 \%)$. From the final sample, $59.17 \%(n=832)$ were women. The average number of years of school attendance was 6.31 ( \pm standard deviation [SD] of 4.9) years; about $43.92 \%$ of participants were married or cohabiting; and $10.39 \%(n=142)$ lived alone. Regarding financial status, about $46.52 \%(n=588)$ of patients reported that their income barely covered their financial needs. As for the factors associated with the health care process, the average waiting time between arrival and admission was $4.8 \mathrm{~h}$ ( \pm SD 5.94), $41.4 \%$ of older adults had not previously gone to an ED, and in the case of recurrence of the same symptoms or medical reason, 37.67\%) $(n=524)$ delayed seeking attention at the ED. The average stay in the ED was $100.79( \pm 67.2)$ hours and 699 subjects (49.7\%) were hospitalized to a general ward after ED admission (Table 1).

The main reason for emergency admission was gastrointestinal problems (17.78\%), followed by nonspecific symptoms (12.52\%). An average score of 3.54 ( \pm SD 3.69) was reported in the visual analog scale of pain (0-10). Mean handgrip strength was $4.49 \mathrm{~kg}( \pm$ SD 6.81). The report of at least one fall within the previous year occurred in $59.53 \%$ of patients $(n=837)$. The median number of medications was three (interquartile range $[\mathrm{IQR}]=0-16$ ), whereas the median number of the sum of chronic diseases was four. Among study participants, $68.49 \%$ reported depressive symptoms. The Barthel index had an average score of $70.29( \pm$ SD 30.08), and the average score of the Mini-mental State Examination (MMSE) was 19.41 ( \pm SD 6.32 ). A total of $82.36 \%$ of study participants had two or more points (high risk) using the ISAR tool and $45.18 \%$ were scored as frail using the FRAIL scale (see Table 1). Finally, $49.7 \%$ patients $(n=699)$ were hospitalized (internal medicine wards).

The bivariate analysis for mortality for the sociodemographic variables showed significant differences for age $[78.2$ years $( \pm$ SD 8.3$)$ and 76.3 years $( \pm S D \quad 7.8)$ ] for non-survivors and survivors, respectively $(p=0.002)$. Factors associated with the healthcare process were statistically significant for delayed arrival to the $\operatorname{ED}(p=0.048)$, the number of hours in the ED $[111.62( \pm S D$ 63.18) for non-survivors versus $97.84( \pm \mathrm{SD} 68)$ for survivors $](p<$ $0.001)$, and any referral to hospitalization $(p=<0.001)$. Hand grip strength was significantly higher in survivors (4.81 vs $3.37, p=0.001$ ). Regarding the MMSE, the mean score was $(19.41$ vs $17.8, p<0.001)$ and the Barthel index mean score was $(72.16$ vs $63.32, p<0.001)$. There was also a significant difference between survivors and non-survivors. Finally, both the ISAR and FRAIL scale proportions were significantly different between survivors and non-survivors during the follow-up period (Table 1).

Regarding the survival analysis, variables which were statistically significant according to the bivariate analysis are shown in the different KMC curves (Fig. 2). Those variables with a $p$-value $<0.2$ in the bivariate analysis were included in a Cox regression unadjusted model and three models were analyzed: all patients, patients not referred to hospitalization $(n=682)$, and patients referred to hospitalization $(n=699)$ in which age, length of stay in the ED, and referral to hospitalization were significant. Neurological problems were also significant except in the group with all patients (Table 2).

A simplified Cox model was obtained using all significant variables in the "all patients" model given in Table 2, including the intervention and other variables significant at a 0.1 level (Table 3). Considering the hazard ratio (HR) of death in the model with all patients, we observed that age remained significant $(\mathrm{HR}=1.02$ confidence interval [CI] 95\% 1.004-1.04, $p=0.014)$, and education level was significant (HR $=1.04$, CI 95\% 1.00 $1.07, p=0.020)$. HR for length of stay was 1.004 (CI $1.002-1.006, p<0.01$ ), grip strength was 0.97 (CI 95\% $0.95-1.00, p=0.052$ ), and the MMSE score was 0.97 (CI $95 \% 0.95-0.99, p<=0.001)$. HR for residents trained for geriatric care intervention was 0.70 , with a marginal significance level in the limit, (CI 95\% 0.48-1.02, $p=0.06$ ) (Table 3$)$. In the model of those subjects without referral 


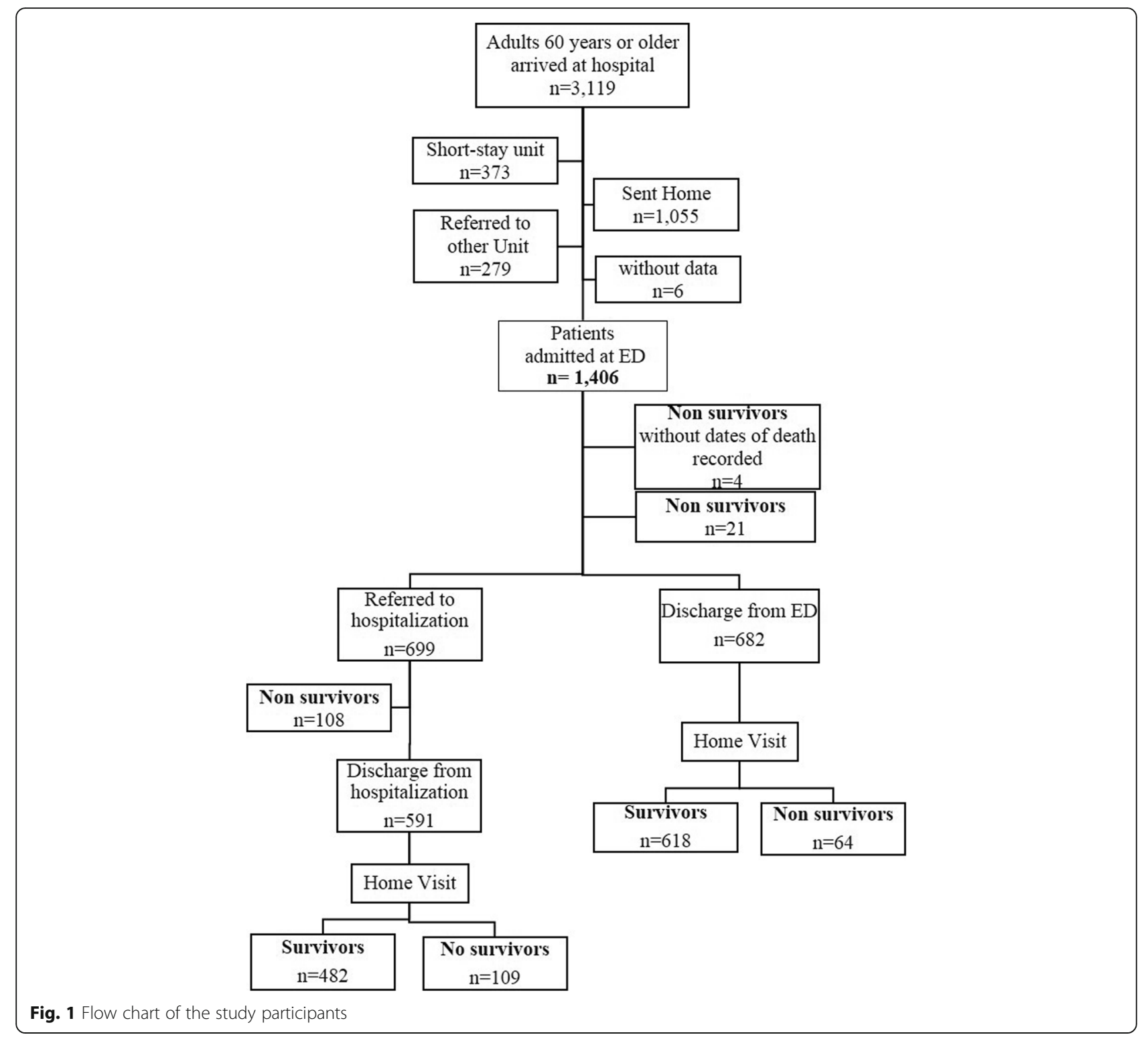

to be hospitalized, only the MMSE maintained significance ( $\mathrm{HR}=0.94$ CI 95\% 0.90-0-99, $\mathrm{p}=0.02)$. In contrast, for those with referral to be hospitalized, significant variables were age, education level, length of stay in the ED and handgrip strength (Table 3).

In a third simplified Cox model considering all patients, age was also significant, as was length of stay in the ED, the presence of residents trained for geriatric care intervention, and the FRAIL scale, which obtained an HR of 1.34 (95\% CI, 1.02-1.76; $p=0.033$ ) (Table 4). Age was the only significant variable in the model including only patients not referred for hospitalization $(\mathrm{HR}=1.04 \mathrm{CI} 95 \% 1.002-1.069, \mathrm{p}=0.03)$ and all variables were significant in the model with patients referred to hospitalization (Table 4).

\section{Discussion}

This study demonstrates high mortality among older persons (21.7\%) in two Mexican public general, non-specialized, hospitals and it reveals that $71 \%$ of the total deaths occurred during hospitalization after a visit to, and referral from, the ED. An associated factor to mortality that appears to be important is the length of stay in the ED. In all analysis, this variable was statistically significant and it may be explained as the presence of inappropriate processes of care at the ED. When a simplified Cox model was executed, hand grip strength was significant only for the group referred to hospitalization. It is plausible to think that patients referred to hospitalization were deteriorated and functionality was seriously affected. 
Table 1 Bivariate analysis of survival by variable categories

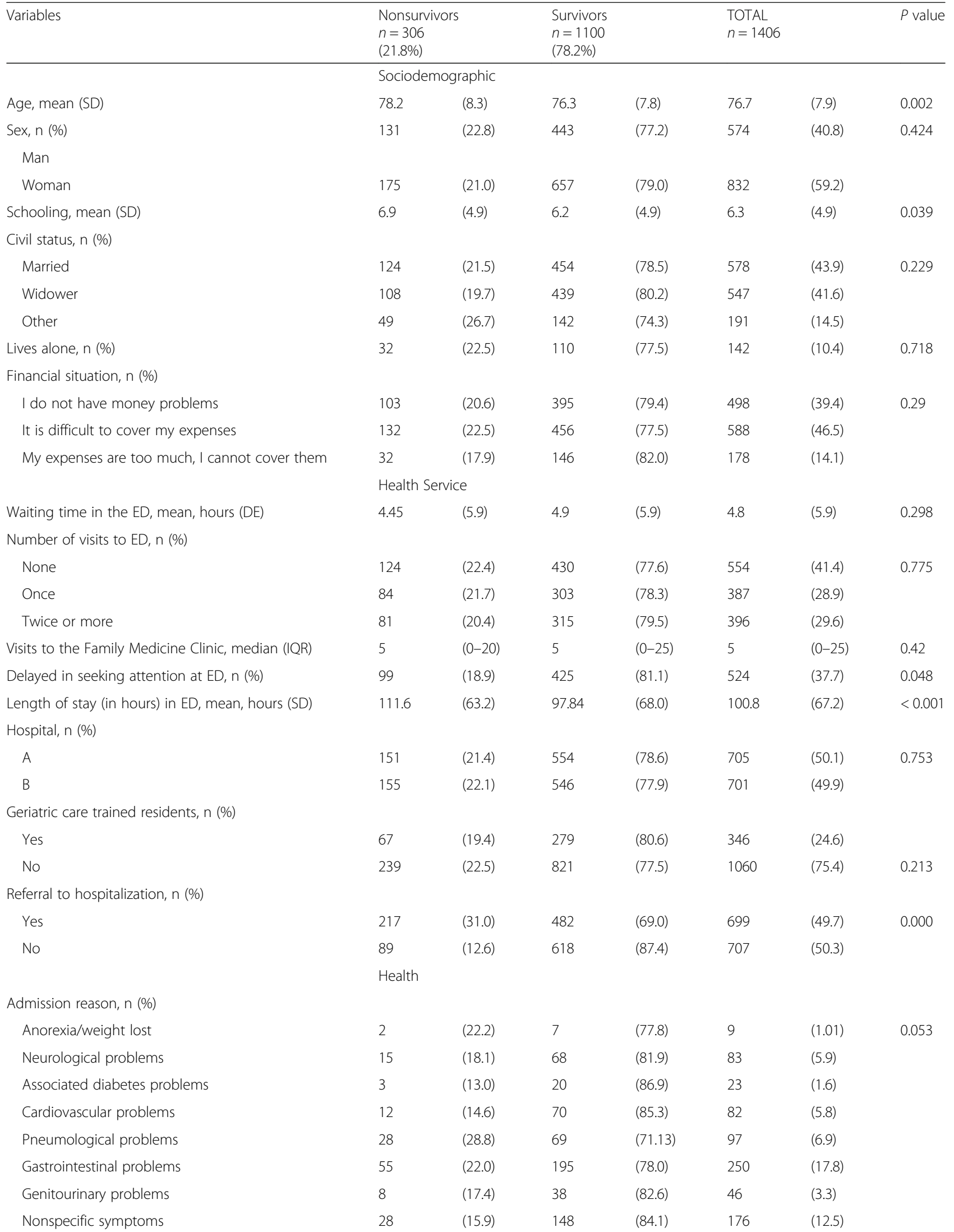


Table 1 Bivariate analysis of survival by variable categories (Continued)

\begin{tabular}{|c|c|c|c|c|c|c|c|}
\hline \multirow{2}{*}{$\begin{array}{l}\text { Variables } \\
\text { Procedures/other services }\end{array}$} & \multicolumn{2}{|c|}{$\begin{array}{l}\text { Nonsurvivors } \\
n=306 \\
(21.8 \%)\end{array}$} & \multicolumn{2}{|c|}{$\begin{array}{l}\text { Survivors } \\
n=1100 \\
(78.2 \%)\end{array}$} & \multicolumn{2}{|c|}{$\begin{array}{l}\text { TOTAL } \\
n=1406\end{array}$} & \multirow[t]{2}{*}{$P$ value } \\
\hline & 7 & $(13.4)$ & 45 & $(86.6)$ & 52 & $(3.7)$ & \\
\hline Other reasons & 15 & $(20.8)$ & 57 & $(79.2)$ & 72 & $(5.1)$ & \\
\hline Nonspecified & 133 & $(25.7)$ & 383 & $(74.3)$ & 516 & $(36.7)$ & \\
\hline Number of admission reasons, median (RIC) & 2 & $(1-7)$ & 2 & $(1-6)$ & 2 & $(1-7)$ & 0.69 \\
\hline \multicolumn{8}{|l|}{ Delirium scale changes, n (\%) } \\
\hline Improved & 80 & $(26.5)$ & 222 & $(73.5)$ & 302 & $(21.5)$ & \multirow[t]{3}{*}{$<0.001$} \\
\hline Same & 202 & $(19.3)$ & 845 & $(80.7)$ & 1047 & $(74.5)$ & \\
\hline Worsened & 24 & $(42.1)$ & 33 & $(57.9)$ & 57 & $(4.0)$ & \\
\hline Visual analogue scale of pain, mean (SD) & 3.39 & $(3.7)$ & 3.57 & (3.9) & 3.54 & $(3.7)$ & 0.475 \\
\hline Grip strength, mean (SD) & 3.37 & $(5.6)$ & 4.81 & $(7.1)$ & 4.49 & $(6.8)$ & 0.001 \\
\hline Falls, n (\%) & 180 & $(21.5)$ & 657 & $(78.5)$ & 837 & $(59.5)$ & 0.776 \\
\hline Number of medications, median (IQR) & 3 & $(0-12)$ & 3 & $(0-16)$ & 3 & $(0-16)$ & 0.112 \\
\hline Feeling sad in the last two weeks, n (\%) & 128 & $(20.8)$ & 485 & $(79.2)$ & 613 & $(68.5)$ & 0.221 \\
\hline Charlson index, median (RIC) & 4 & $(1-13)$ & 6 & $(5-10)$ & 4 & $(1-13)$ & 0.896 \\
\hline MMSE, mean (SD) & 17.8 & $(7.0)$ & 19.4 & (6) & 19.41 & (6.3) & $<0.001$ \\
\hline Barthel index, mean (SD) & 63.32 & $(34.2)$ & 72.16 & $(28.6)$ & 70.29 & $(30.1)$ & $<0.001$ \\
\hline ISAR, n (\%) & 198 & $(17.1)$ & 960 & $(82.9)$ & 1158 & $(82.4)$ & 0.001 \\
\hline FRAIL, n (\%) & 134 & $(21.8)$ & 480 & $(78.2)$ & 614 & $(45.2)$ & $<0.001$ \\
\hline
\end{tabular}

The residents trained in geriatric care intervention seemed to be a protective factor in the last model (Table 4) when all patients were analyzed, and it is also significant for those patients referred to hospitalization. In this report, the training model was incorporated as the only other associated factor. Therefore, and in spite of the evident methodological limitations to evaluate the impact of such an intervention, it is possible to conclude that geriatric training of emergency and internal medicine residents is of the most importance.

Utilization patterns of the ED and the hospitalization of older adults are different from those of other age groups, primarily because of multimorbidity, frailty, $\operatorname{cog}$ nitive impairment, depression, and poor self-rated health

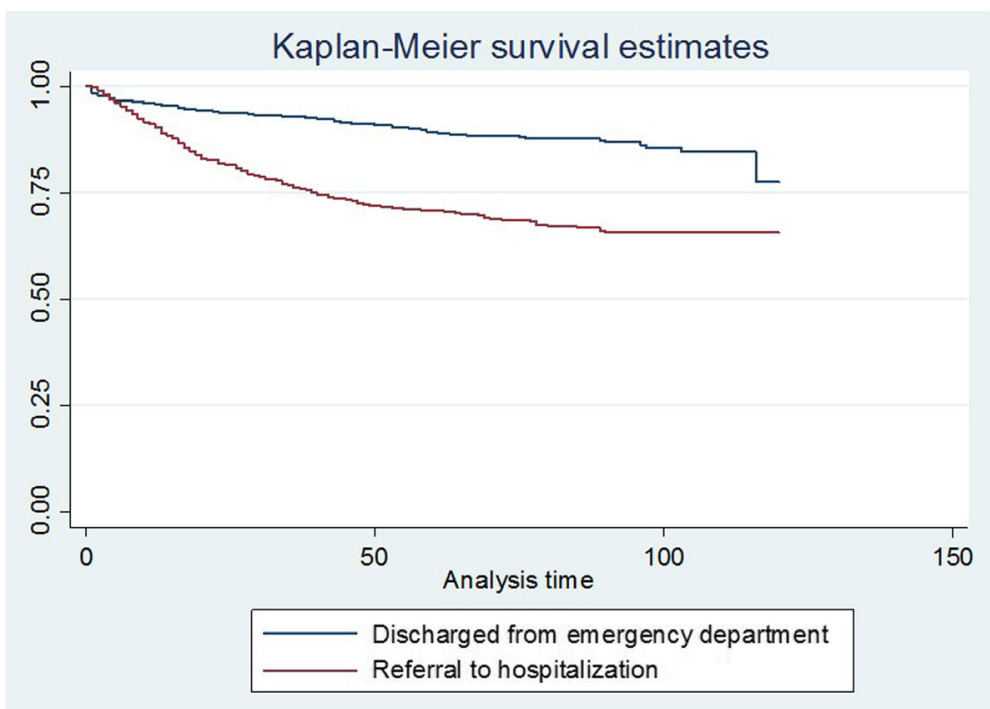

Fig. 2 Kaplan-Meier Curves and Log-rank tests for group referred to hospitalization versus discharged from ED 
Table 2 Cox regression (variables included: those with significance $<0.2$ in the bivariate analysis, as well as sex and geriatric care trained residents)

\begin{tabular}{|c|c|c|c|c|c|c|c|c|c|}
\hline \multirow{3}{*}{$\begin{array}{l}\text { Variable } \\
\text { Age }\end{array}$} & \multicolumn{3}{|c|}{ All patients } & \multicolumn{3}{|c|}{$\begin{array}{l}\text { Discharged from emergency } \\
\text { department } n=682\end{array}$} & \multicolumn{3}{|c|}{ Referral to hospitalization $n=699$} \\
\hline & \multicolumn{2}{|c|}{$\mathrm{HR}(95 \% \mathrm{Cl})$} & \multirow{2}{*}{$\begin{array}{l}\text { Significance } \\
0.007\end{array}$} & \multicolumn{2}{|l|}{$\begin{array}{l}\mathrm{HR} \\
(95 \% \mathrm{Cl})\end{array}$} & \multirow{2}{*}{$\begin{array}{l}\text { Significance } \\
0.04\end{array}$} & \multicolumn{2}{|c|}{$\begin{array}{l}\mathrm{HR} \\
(95 \% \mathrm{Cl})\end{array}$} & \multirow{2}{*}{$\begin{array}{l}\text { Significance } \\
0.38\end{array}$} \\
\hline & 1.03 & $(1.00-1.05)$ & & 1.04 & $(1.00-1.09)$ & & 1.02 & $(0.99-1.05)$ & \\
\hline Woman & 0.75 & $(0.52-1.07)$ & 0.117 & 0.45 & $(0.22-0.90)$ & 0.02 & 0.82 & $(0.52-1.28)$ & 0.38 \\
\hline Schooling & 1.03 & $(0.99-1.06)$ & 0.145 & 1.00 & $(0.93-1.08)$ & 0.79 & 1.03 & $(0.98-1.07)$ & 0.14 \\
\hline Length of stay in ED & 1.00 & $(1.00-1.01)$ & $<0.001$ & 1.00 & $(0.99-1.00)$ & 0.12 & 1.01 & $(1.00-1.01)$ & 0.001 \\
\hline Delayed in seekig attention at ED & 0.79 & $(0.54-1.15)$ & 0.22 & 1.99 & $(0.99-3.98)$ & 0.05 & 0.52 & $(0.31-0.86)$ & 0.001 \\
\hline Referral to hospitalization & 2.79 & $(1.89-4.10)$ & $<0.001$ & - & - & - & - & - & - \\
\hline $\begin{array}{l}\text { Geriatric care trained residents model } \\
\text { (Hospital A final) }\end{array}$ & 0.64 & $(0.39-1.11)$ & 0.115 & 1.02 & $(0.42-2.47)$ & 0.95 & 0.64 & $(0.33-1.24)$ & 0.18 \\
\hline \multicolumn{10}{|l|}{ Health problems: } \\
\hline Anorexia/weight loss & 4.86 & $(0.49-48.07)$ & 0.176 & $2.92 \mathrm{e}-15$ & $(0-0)$ & 1.00 & 60.64 & $(4.61-796.77)$ & 0.002 \\
\hline Neurologic & 0.80 & $(0.32-2.04)$ & 0.653 & 5.88 & $(1.73-19.89)$ & 0.004 & 0.18 & $(0.02-1.36)$ & 0.09 \\
\hline Diabetes-associated & 1.39 & $(0.43-4.50)$ & 0.587 & 0.69 & $(0.08-5.68)$ & 0.73 & 1.61 & $(0.37-7.00)$ & 0.52 \\
\hline Cardiovascular & 1.11 & $(0.52-2.34)$ & 0.791 & 1.45 & $(0.18-11.37)$ & 0.72 & 1.15 & $(0.50-2.61)$ & 0.73 \\
\hline Pneumological & 1.68 & $(1.03-2.75)$ & 0.037 & 1.07 & $(0.34-3.31)$ & 0.90 & 1.66 & $(0.94-2.93)$ & 0.07 \\
\hline Gastrointestinal & 1.04 & $(0.64-1.68)$ & 0.879 & 1.09 & $(0.46-2.60)$ & 0.83 & 0.87 & $(0.47-1.60)$ & 0.67 \\
\hline Genitourinary & 0.20 & $(0.03-1.42)$ & 0.107 & $2.16 \mathrm{e}-15$ & $(0-0)$ & 0.90 & 0.29 & $(0.03-2.15)$ & 0.22 \\
\hline \multicolumn{10}{|l|}{ Delirium scale changes, n (\%) } \\
\hline Same & \multicolumn{3}{|c|}{ Reference } & & & & & & \\
\hline Improved & 0.81 & $(0.39-1.68)$ & 0.581 & 0.69 & $(0.19-2.47)$ & 0.57 & 0.63 & $(0.25-1.60)$ & 0.34 \\
\hline Worsened & 1.61 & $(0.55-4.73)$ & 0.383 & 1.16 & $(0.13-10.03)$ & 0.89 & 2.21 & $(0.63-7.76)$ & 0.21 \\
\hline Grip strength & 0.97 & $(0.94-1.00)$ & 0.101 & 1.00 & $(0.96-1.05)$ & 0.71 & 0.93 & $(0.88-0.98)$ & 0.007 \\
\hline Number of medications & 1.05 & $(0.99-1.12)$ & 0.108 & 1.17 & $(1.03-1.33)$ & 0.01 & 1.03 & $(0.95-1.11)$ & 0.37 \\
\hline Mini-mental state examination score & 0.98 & $(0.95-1.01)$ & 0.291 & 0.97 & $(0.90-1.04)$ & 0.41 & 0.99 & $(0.95-1.03)$ & 0.38 \\
\hline Barthel index score & 0.99 & $(0.99-1.00)$ & 0.171 & 0.99 & $(0.98-1.01)$ & 0.67 & 0.99 & $(0.98-1.00)$ & 0.14 \\
\hline FRAIL dichotomic $(\geq 2)$ & 0.93 & $(0.63-1.39)$ & 0.738 & 0.43 & $(0.18-1.03)$ & 0.06 & 1.18 & $(0.73-1.89)$ & 0.48 \\
\hline ISAR dichotomic $(\geq 2)$ & 1.11 & $(0.63-1.96)$ & 0.707 & 2.05 & $(0.57-7.32)$ & 0.26 & 0.83 & $(0.43-1.60)$ & 0.59 \\
\hline
\end{tabular}

$[28,29]$. It has been argued that older adults are the main cause of the exponential increase in health care costs [30]. However, there are many reasons beyond demographic transition which do not only involve cultural factors and clinical variables, but also involve health staff resistance to change, ageism, inadequate or incomplete geriatric training, and poor accessibility to emergency services [31], among others. A remarkable effort has been made by different agencies and societies worldwide to increase the knowledge and geriatric competencies of health professionals. However, effective interventions to insert the geriatric perspective in health staff are not easy and there is a lack of evidence of interventions [32].

Several studies have examined the deleterious effects of length of stay in the emergency department and hospitals with respect to the functionality and quality of life of older adults [33]. In this context, our findings revealed that in addition to the general traditional factors associated with mortality (age and education level), geriatric conditions (delirium, cognitive impairment, multi-medication, and frailty) play an important role for older adults being at risk of death. Our findings are consistent with the results of previous reports $[6,10,34]$. A delay in seeking attention at the ED and the time spent in the ED were variables that correlated significantly with mortality; both maintain significance for the group of participants referred for hospitalization in the Cox regression adjusted for all significant variables (see Table 2). Length of stay at the ED was relevant to participants that were referred for hospitalization. Although it could be argued that this finding represents a selection bias, these variables reflect serious difficulties in providing emergency care. The variables also reflect a deferral of 
Table 3 Simplified Cox regression model

\begin{tabular}{|c|c|c|c|c|c|c|c|c|c|}
\hline \multirow[t]{2}{*}{ Variable } & \multicolumn{3}{|c|}{ With only significant variables } & \multicolumn{3}{|c|}{$\begin{array}{l}\text { Discharged from emergency } \\
\text { department } n=682\end{array}$} & \multicolumn{3}{|c|}{$\begin{array}{l}\text { Referral to hospitalization } \\
n=699\end{array}$} \\
\hline & \multicolumn{2}{|c|}{$\overline{\mathrm{HR}}(95 \% \mathrm{Cl})$} & \multirow{2}{*}{$\begin{array}{l}\text { Significance } \\
0.014\end{array}$} & \multicolumn{2}{|c|}{$\mathrm{HR}(95 \% \mathrm{Cl})$} & \multirow{2}{*}{$\begin{array}{l}\text { Significance } \\
0.073\end{array}$} & \multicolumn{2}{|c|}{$\overline{\mathrm{HR}}(95 \% \mathrm{Cl})$} & \multirow{2}{*}{$\begin{array}{l}\text { Significance } \\
0.05\end{array}$} \\
\hline Age & 1.02 & $(1.00-1.04)$ & & 1.03 & $(0.99-1.06)$ & & 1.02 & $(0.99-1.04)$ & \\
\hline Schooling & 1.04 & $(1.01-1.07)$ & 0.020 & 1.01 & $(0.95-1.07)$ & 0.61 & 1.04 & $(1.00-1.08)$ & 0.02 \\
\hline Length of stay in ED & 1.00 & $(1.00-1.01)$ & 0.001 & 1.00 & $(0.99-1.00)$ & 0.469 & 1.00 & $(1.00-1.01)$ & 0.001 \\
\hline Referral to hospitalization & 2.86 & $(2.08-3.92)$ & $<0.000$ & - & - & - & - & - & - \\
\hline $\begin{array}{l}\text { Geriatric care trained residents model (Hospital A } \\
\text { final) }\end{array}$ & 0.70 & $(0.48-1.03)$ & 0.067 & 1.02 & $(0.41-1.71)$ & 0.636 & 0.66 & $(0.42-1.04)$ & 0.076 \\
\hline Grip strength & 0.97 & $(0.95-1.00)$ & 0.052 & 1.01 & $(0.97-1.05)$ & 0.45 & 0.95 & $(0.92-0.99)$ & 0.009 \\
\hline Mini-mental state examination score & 0.97 & $(0.95-0.99)$ & 0.000 & 0.94 & $(0.90-0.99)$ & 0.02 & 0.98 & $(0.95-1.05)$ & 0.115 \\
\hline
\end{tabular}

attention given to specific groups of patients and the inability of health staff to identify patients at risk in a timely and accurate manner [35]. As highlighted by Adams and Gerson [36], the current model of ED care was designed for acutely ill and injured patients, not slow-moving, functionally affected geriatric patients with multimorbidity.

We believe that our results are relevant and that the methodological components of the study were supervised carefully in spite of difficulties in the ED setting. We also believe that the aging research conducted in this country, Mexico, is important and could be useful to countries facing similar situations where chaos in the ED is usual. Of course, our study has some methodological limitations. Patients that were not admitted to the ED may represent a selection bias, underestimating the effect if those patients were seriously ill and transferred to another hospital.

Finally, frailty appears to be an important variable associated with mortality, as proven to be for other populations and a wide variety of settings. Proper attention given to frail persons in EDs is a pivotal issue. Detecting frailty status is crucial and the development of standard care protocols is an important area of research [37].
Creating public policies that support funding for developing quality patient care strategies and gathering scientific evidence, as well as promoting structural adjustments in health care institutions (to care for the needs of older adults), should be encouraged.

Many developing countries and emerging economies face major challenges in a bid to effectively meet the health care needs of a growing older population. Mexico is not an exception in this situation. Aging populations and fragmented health care and social systems combine to provide an inappropriate response to this new scenario.

\section{Conclusions}

Mortality in patients over 60 years old admitted to the ED is high. Factors of mortality are related to the organization of health services and the patient's length of stay in the ED. Also, hand grip strength as a key component of frailty seems to be an important associated factor. The health care system must quickly adjust its response to an aging population and restructure health services to better meet the needs of older individuals. This must be a priority.

Table 4 Regression Model for mortality ${ }^{a}$

\begin{tabular}{|c|c|c|c|c|c|c|c|c|c|}
\hline \multirow{3}{*}{$\begin{array}{l}\text { Variable } \\
\\
\text { Age }\end{array}$} & \multicolumn{3}{|c|}{ With only significant variables } & \multicolumn{3}{|c|}{ Discharged from emergency department $n=682$} & \multicolumn{3}{|c|}{$\begin{array}{l}\text { Referral to hospitalization } \\
n=699\end{array}$} \\
\hline & \multicolumn{2}{|c|}{ HR (95\% Cl) } & \multirow{2}{*}{$\begin{array}{l}\text { Significance } \\
0.012\end{array}$} & \multicolumn{2}{|c|}{$\mathrm{HR}(95 \% \mathrm{Cl})$} & \multirow{2}{*}{$\begin{array}{l}\text { Significance } \\
0.03\end{array}$} & \multicolumn{2}{|c|}{$\mathrm{HR}(95 \% \mathrm{Cl})$} & \multirow{2}{*}{$\begin{array}{l}\text { Significance } \\
0.07\end{array}$} \\
\hline & 1.02 & $(1.00-1.04)$ & & 1.04 & $(1.00-1.07)$ & & 1.07 & $(0.99-1.04)$ & \\
\hline Schooling & 1.02 & $(0.99-1.04)$ & 0.16 & 0.99 & $(0.94-1.04)$ & 0.77 & 1.03 & $(0.99-1.06)$ & 0.08 \\
\hline Length of stay in ED & 1.00 & $(1.00-1.00)$ & 0.006 & 1.00 & $(0.99-1.07)$ & 0.31 & 1.00 & $(1.00-1.01)$ & 0.012 \\
\hline Referral to hospitalization & 3.12 & $(2.29-4.24)$ & $<0.001$ & - & - & - & - & - & - \\
\hline $\begin{array}{l}\text { Geriatric care trained residents } \\
\text { model (Hospital A final) }\end{array}$ & 0.66 & $(0.46-0.96)$ & 0.031 & 0.79 & $(0.39-1.61)$ & 0.53 & 0.65 & $(0.42,1.01)$ & 0.05 \\
\hline FRAIL (dichotomic) ( $\geq 2$ ) & 1.34 & $(1.02-1.76)$ & 0.033 & 0.80 & $(0.46-1.38)$ & 0.42 & 1.59 & $(1.15-2.18)$ & 0.005 \\
\hline
\end{tabular}

${ }^{\mathrm{a}}$ Same model than Table 3 without grip strength or MMSe and including Frail 


\section{Abbreviations}

CAM: Confusion Assessment Method; Cl: Confidence interval; ED: Emergency department; HR: Hazard ratios; IMSS: Instituto Mexicano del Seguro Social; IQR: Interquartile range; ISAR: Identification of Seniors at Risk; KMC: KaplanMeier curves; MMSE: Mini-Mental State Examination; SAGE: Study on Global Ageing and Adult Health; SD: Standard deviation

\section{Funding}

This project was supported by a grant from the Mexican Institute of Social Security (FIS/IMSS/PROT/PRIO 12/018).

\section{Availability of data and materials}

The dataset generated and/or analyzed during the current study are not publicly available as data sharing was not mentioned during our ethics application. The datasets supporting the conclusions of this article are available upon request from the corresponding author.

\section{Authors' contributions}

CGP conceived of the presented idea and made substantial contributions to the conception, design, analysis, and interpretation of the data. CGP was involved in drafting and revising the the manuscript critically for important intellectual content. MUPZ made substantial contributions to the analysis and interpretation of the data and was involved in revising the manuscript critically for important intellectual content. LVRJ made substantial contributions through the acquisition of the data and was involved in drafting the manuscript. SSG was involved in drafting and revising the manuscript critically for important intellectual content. RRA made substantial contributions to the analysis and interpretation of the data and was involved in revising the manuscript critically for important intellectual content. PTV made substantial contributions through the acquisition of the data and was involved in drafting the manuscript. All authors gave final approval of the version to be published and agreed to be accountable for all aspects of the work in ensuring that questions related to the accuracy or integrity of any part of the work would be appropriately investigated and resolved.

\section{Ethics approval and consent to participate}

The research protocol was approved by the Ethics and Scientific Commission of IMSS (R2011-785-056). An informed written consent was signed by each willing participant or by a representative. Patients were free to refuse to take part in the study or to withdraw from it at any stage on simple request. Patients were advised that refusing to participate or withdrawing from the study would not produce consequences or any alteration to the medical care provided.

\section{Consent for publication}

Not applicable.

\section{Competing interests}

The authors declare that they have no competing interests.

\section{Publisher's Note}

Springer Nature remains neutral with regard to jurisdictional claims in published maps and institutional affiliations.

\section{Author details \\ ${ }^{1}$ Dirección de Investigación, Instituto Nacional de Geriatría, Periférico Sur No. 2767, Mexico City, Mexico. ${ }^{2}$ Instituto Nacional de Psiquiatría Ramón de la Fuente Muñiz, Mexico City, Mexico. ${ }^{3}$ Unidad de Investigación en Epidemiología y Servicios de Salud, Área Envejecimiento, Mexico City, Mexico. ${ }^{4}$ Facultad de Ciencias. Universidad Nacional Autónoma de México, Mexico City, Mexico.}

Received: 7 July 2017 Accepted: 10 June 2018

Published online: 18 June 2018

\section{References}

1. Gutiérrez-Robledo LMPA, Téllez Rojo MM, Wong R. Introduction. Salud Publica Mex. 2015;57(1):S2-5.

2. Prince MJ, Wu F, Guo Y, Gutierrez Robledo LM, O'Donnell M, Sullivan R, et al. The burden of disease in older people and implications for health policy and practice. Lancet. 2015;385(9967):549-62.
3. Beard JR, Officer A, De Carvalho IA, Sadana R, Pot AM, Michel JP, et al. The world report on ageing and health: a policy framework for healthy ageing. Lancet. 2016;387(10033):2145-54.

4. World Health Organization. World Report on Ageing and Health; 2015. p. 1-247.

5. Sanders AB, Morley JE. The older person and the emergency department. J Am Geriatr Soc. 1993:41(8):880-2.

6. Salvi F, Morichi V, Grilli A, Giorgi R, Spazzafumo L, Polonara S, et al. A geriatric emergency service for acutely ill elderly patients: pattern of use and comparison with a conventional emergency department in Italy. J Am Geriatr Soc. 2008;56(11):2131-8.

7. Lee JT, Hamid F, Pati S, Atun R, Millett C. Impact of noncommunicable disease multimorbidity on healthcare utilisation and out-of-pocket expenditures in middle-income countries: cross sectional analysis. PLoS One. 2015;10(7):e0127199

8. González-González C, Sánchez-García S, Juárez-Cedillo T, Rosas-Carrasco O, Gutiérrez-Robledo LM, García-Peña C. Health care utilization in the elderly Mexican population: expenditures and determinants. BMC Public Health. 2011;11:192

9. Mion LC, Palmer RM, Meldon SW, Bass DM, Singer ME, Payne SMC, et al. Case finding and referral model for emergency department elders: a randomized clinical trial. Ann Emerg Med. 2003;41(1):57-68.

10. Gunnarsdottir OS, Rafnsson V. Mortality of the users of a hospital emergency department. Emergency medicine journal : EMJ. 2006;23:269-73.

11. Byrne DG, Chung SL, Bennett K, Silke B. Age and outcome in acute emergency medical admissions. Age Ageing. 2010;39(6):694-8.

12. Grossmann FF, Zumbrunn T, Frauchiger A, Delport $K$, Bingisser R, Nickel CH. At risk of undertriage? Testing the performance and accuracy of the emergency severity index in older emergency department patients. Ann Emerg Med. 2012;60(3):317-25.

13. Sost $G$, Jouanny P. Urgences gériatriques. EMC - Traité de médecine AKOS 2006;1(1):1-5.

14. Nickel CH, Messmer AS, Geigy N, Misch F, Mueller B, Dusemund F, et al. Stress markers predict mortality in patients with nonspecific complaints presenting to the emergency department and may be a useful risk stratification tool to support disposition planning. Acad Emerg Med. 2013; 20(7):670-9.

15. Beynon T, Gomes B, Murtagh FEM, Glucksman E, Parfitt A, Burman R, et al. How common are palliative care needs among older people who die in the emergency department? BMJ Support Palliat Care. 2011;1(2):184-8.

16. Rodríguez-Molinero A, López-Diéguez M, Tabuenca Al, De La Cruz JJ, Banegas JR. Physicians' impression on the elders' functionality influences decision making for emergency care. Am J Emerg Med. 2010;28(7):757-65.

17. De Decker L, Beauchet O, Gouraud-Tanguy A, Berrut G, Annweiler C, Le Conte P. Treatment-limiting decisions, comorbidities, and mortality in the emergency departments: a cross-sectional elderly population-based study. Journal of Nutrition, Health and Aging. 2012;16(10):914-8.

18. Ely EW, Margolin R, Francis J, May L, Truman B, Dittus R, et al. Evaluation of delirium in critically ill patients: validation of the confusion assessment method for the intensive care unit (CAM-ICU). Crit Care Med. 2001;29(7):1370-9.

19. Price DD, McGrath PA, Rafii A, Buckingham B. The validation of visual analogue scales as ratio scale measures for chronic and experimental pain. Pain. 1983;17(1):45-56.

20. Favela JJ, Castro LA, Franco-Marina F, Sánchez-García S, Juárez-Cedillo T, Espinel Bermudez C, et al. Nurse home visits with or without alert buttons versus usual care in the frail elderly: a randomized controlled trial. Clin Interv Aging. 2013;8:85-95.

21. Hustey FM. The use of a brief depression screen in older emergency department patients. Acad Emerg Med. 2005;12(9):905-8.

22. Reyes De-Beaman S, Beaman PE, Garcia-Pena C, Jagger C, Villa MA, Heres J, et al. Validation of a modified version of the mini-mental state examination (MMSE) in Spanish. Aging Neuropsychol Cogn. 2004;11, 11(1)

23. Folstein MF, Folstein SE, McHugh PR. "Mini-mental state". A practical method for grading the cognitive state of patients for the clinician. J Psychiatr Res. 1975;12(3):189-98.

24. Wylie CM. Measuring end results of rehabilitation of patients with stroke. Public Health Rep. 1967;82(10):893-8.

25. McCusker J, Bellavance F, Cardin S, Trépanier S, Verdon J, Ardman O. Detection of older people at increased risk of adverse health outcomes after an emergency visit: the ISAR screening tool. J Am Geriatr Soc. 1999; 47(10):1229-37. 
26. Morley JE, Malmstrom TK, Miller DK. A simple frailty questionnaire (FRAIL) predicts outcomes in middle aged african americans. Journal of Nutrition, Health and Aging. 2012;16(7):601-8.

27. Lee ET, Wenyu Wang J. Statistical methods for survival data analysis. Third edit. Oklahoma: John Wiley \& Sons; 1992. 496 p

28. McCusker J, Karp I, Cardin S, Durand P, Morin J. Determinants of emergency department visits by older adults: a systematic review. Acad Emerg Med. 2003;10(12):1362-70.

29. Shah MN, Rathouz PJ, Chin MH. Emergency department utilization by noninstitutionalized elders. Academic emergency medicine : official journal of the Society for Academic Emergency Medicine. 2001;8(3):267-73.

30. Yoon J, Zulman D, Cott J, Maciejewski M. Costs associated with multimorbidity among VA patients. Med Care. 2014;52(3 Suppl 2):S31-6.

31. Fan L, Shah MN, Veazie PJ, Friedman B. Factors associated with emergency department use among the rural elderly. J Rural Health. 2011;27(1):39-49.

32. Capezuti E, Boltz M, Cline D, Al E. Nurses improving Care for Healthsystem Elders - a model for optimising the geriatric nursing practice environment. J Clin Nurs. 2012;21(21-22):3117-25.

33. Aminzadeh F, Dalziel WB. Older adults in the emergency department: a systematic review of patterns of use, adverse outcomes, and effectiveness of interventions. Ann Emerg Med. 2002;39(3):238-47.

34. Chang H-H, Tsai S-L, Chen C-Y, Liu W-J. Outcomes of hospitalized elderly patients with geriatric syndrome: report of a community hospital reform plan in Taiwan. Arch Gerontol Geriatr. 2010;50(Suppl 1):S30-3.

35. Legramante J, Morciano L, Lucaroni F, Gilardi F, Caredda E, Pesaresi A, et al. Frequent use of emergency departments by the elderly population when continuing care is not well established. PLoS One. 2016;11(12):e0165939.

36. Adams J, Gerson L. A new model for emergency care of geriatric patients. Acad Emerg Med. 2003;10(3):271-4.

37. Duaso E, López SA. Assessing frail patients in the emergency department Emergencias. 2009;21:362-9.

Ready to submit your research? Choose BMC and benefit from:

- fast, convenient online submission

- thorough peer review by experienced researchers in your field

- rapid publication on acceptance

- support for research data, including large and complex data types

- gold Open Access which fosters wider collaboration and increased citations

- maximum visibility for your research: over $100 \mathrm{M}$ website views per year

At BMC, research is always in progress.

Learn more biomedcentral.com/submissions 